\title{
Depression Treatment Preferences of Hispanic Individuals: Exploring the Influence of Ethnicity, Language, and Explanatory Models
}

\author{
Erik Fernandez y Garcia, MD, MPH, Peter Franks, MD, Anthony Jerant, MD, \\ Robert A. Bell, PhD, and Richard L. Kravitz, MD, MSPH
}

Purpose: There is uncertainty regarding Hispanic individuals' depression treatment preferences, particularly regarding antidepressant medication, the most available primary care option. We assessed whether this uncertainty reflected heterogeneity among subgroups of Hispanic persons and investigated possible mechanisms. Specifically, we examined factors associated with medication preferences in non-Hispanic white and Spanish-speaking and English-speaking Hispanic persons.

Methods: We analyzed data from a follow-up telephone interview of 839 non-Hispanic white and 139 Hispanic respondents originally surveyed via the 2008 California Behavioral Risk Factor Surveillance System. Measures included treatment preferences (for treatment plans including vs not including antidepressants); depression history and current symptoms; sociodemographics; and psychological measures.

Results: Compared with non-Hispanic white respondents (adjusting for age, sex, history of depression diagnosis, and current depression symptoms), Spanish-speaking Hispanic (adjusted odds ratio [A0R] 0.41; 95\% CI, 0.19-0.90) but not English-speaking Hispanic (AOR, 1.18; 95\% CI, 0.60-2.33) respondents had a lower preference for antidepressant inclusive options. Endorsing a biomedical explanation of depression was associated with a preference for antidepressant inclusive options (AOR, 4.76; 95\% CI, 3.13-7.14) for all respondents and accounted for the effect of Spanish-language interview. Accounting for other factors did not change these relationships, although older age and history of depression diagnosis remained significant predictors of antidepressant inclusive treatment preference for all respondents.

Conclusions: Spanish-language interview and less belief in a biomedical explanation for depression were associated with Hispanic respondents' lower preferences for pharmacologic treatment of depression; ethnicity was not. Understanding treatment preferences and illness beliefs could help optimize depression treatment in primary care. (J Am Board Fam Med 2011;24:39-50.)

Keywords: Depression, Illness Representation Models, Minority Health, Treatment Preferences

Disparities in depression care between Hispanic and non-Hispanic white patients, such as underdiagnosis and undertreatment, persist after adjusting for care access barriers. ${ }^{1-3}$ People of Hispanic ethnicity represent a large and growing population in the United States ${ }^{4}$ and, when compared with other

This article was externally peer reviewed.

Submitted 14 May 2010; revised 9 September 2010; accepted 21 September 2010.

From the Department of Pediatrics, Division of General Pediatrics (EFyG), the Departments of Family and Community Medicine (PF, AJ) and Internal Medicine (RLK), and the Center for Healthcare Policy and Research (PF, RAB, RLK), University of California-Davis School of Medicine, and the Department of Communication and Department of Public Health Sciences, University of California-Davis, Davis (RAB). groups, receive a disproportionate amount of depression care in primary care settings. ${ }^{5,6}$ Depression is a common diagnosis for primary care practitioners and depression care disparities are an especially salient problem. Because antidepressants are the most commonly offered therapy in primary

Funding: This project was conducted with support from a National Institute of Mental Health Grant titled "Targeting and Tailoring Messages to Enhance Depression Care" (3R01MH079387). Erik Fernandez y Garcia received additional support from a Diversity Supplement to this parent grant (3R01MH079387-02S1).

Conflict of interest: none declared.

Corresponding author: Erik Fernandez y Garcia, MD, MPH, 2516 Stockton Boulevard, Suite 341, Sacramento, CA 95817 (E-mail: Erik.fernandez@ucdmc.ucdavis.edu). 
care, ${ }^{7,8}$ understanding Hispanic patients' attitudes toward the treatment of depression with medication may facilitate optimal care. ${ }^{9,10}$

Relatively few studies have examined the attitudes of Hispanic individuals toward depression treatment. Karasz and Watkins ${ }^{11}$ found that Hispanic patients feel that both antidepressants and counseling would be helpful treatments, but that counseling would be more helpful. Cooper et $\mathrm{al}^{12}$ found Hispanic and white patients mostly were accepting of both treatments, but Hispanic patients were relatively less accepting of antidepressants and more accepting of counseling. Other studies suggest that Hispanic individuals prefer a combination of antidepressants and counseling over either alone $^{13}$ and prefer counseling over antidepressants ${ }^{14-16}$ at rates equal to ${ }^{16}$ or greater than ${ }^{15}$ white individuals.

Having a clear understanding of Hispanic patients' antidepressant treatment preferences is important because for some patients counseling may be more effective when combined with antidepressant medication, ${ }^{17}$ in primary care antidepressant therapy is far more widely available than counseling, ${ }^{18}$ and preferences for a treatment that is effectively rationed could widen disparities. Though previous studies suggest that Hispanic patients may prefer counseling, mixed findings and methodological limitations temper this conclusion. First, most previous studies involved small or homogeneous samples, precluding exploration of differences among subgroups of Hispanic individuals. This is a key limitation because Hispanic identity subsumes a number of cultural, racial, nativity, and generational groups, with differing patterns of mental health care use. ${ }^{19,20}$ Language preference (English or Spanish) is a frequently measured identifier of heterogeneity among Hispanic persons in both research and clinical resource planning. ${ }^{14,21-23}$ Language is not only a marker of acculturation ${ }^{24}$; it also correlates with other important mediators of depression care preferences such as access to care. ${ }^{25,26}$ Second, previous experiences with and current symptoms of depression (which may influence treatment attitudes ${ }^{16,27}$ ) were inconsistently included in prior analyses. Third, some studies lacked a "no treatment" preference response option, ${ }^{12,13}$ potentially biasing their findings. Finally, few studies explored the beliefs behind patient treatment preferences. Understanding such beliefs could be useful in guiding efforts to mitigate disparities in depression care. ${ }^{16}$

Based on the literature cited above and other literature about treatment attitudes, ${ }^{16,25-36}$ we proposed a conceptual model for the relationship between predictors and mediators of predictors of a preference for treatment options that include antidepressant medication to address these limitations (illustrated in Figure 1). We then resurveyed a sample of respondents to the 2008 California Behavioral Risk Factor Surveillance System (BRFSS) to investigate 2 research questions in the context of the hypothesized model (Figure 1): (1) Is there significant heterogeneity in the preferences for treatment options that include antidepressants among English- or Spanish-speaking Hispanic respondents compared with non-Hispanic white respondents after adjusting for key potential correlates of treatment preference (age, sex, depression history, and current depression symptoms)? (2) To the extent that significant heterogeneity does exist, what factors mediate the differences in Hispanic

Figure 1. Hypothesized relationship of respondent characteristics and mediators of preferences for treatment options that include antidepressant medications.

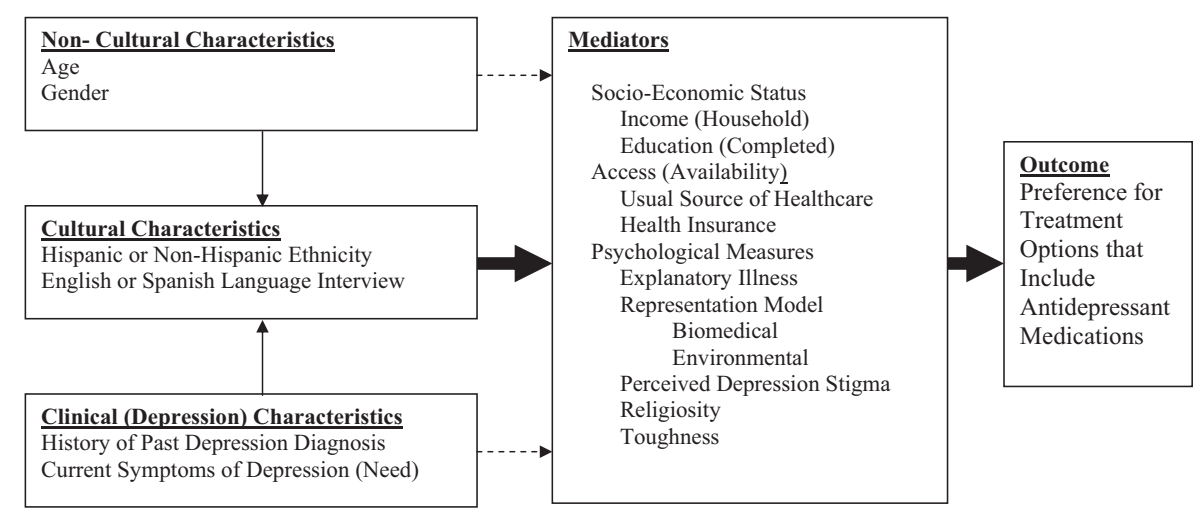


respondent language subgroups' preference for treatment options that include antidepressants? We examined the extent to which Hispanic respondents' attitudes toward antidepressants might be mediated by socioeconomic, health care accessrelated, and psychological factors that have been shown in previous studies to influence attitudes toward medical treatments (depression illness representation models, ${ }^{28-30}$ perceived stigma of depression, ${ }^{31,32}$ toughness, ${ }^{33-35}$ and religiosity ${ }^{30,32,36}$ ) (Figure 1).

\section{Methods \\ Sample}

Patients for the current follow-up study (administered July to December 2008) were sampled from respondents to the California BRFSS survey, originally administered from January through June 2008. Because the focus of the current survey was on attitudes toward and experience with depression and because equal probability sampling would yield too few respondents with a history of depression, patients with a history of depression diagnosis were oversampled (approximately 3-fold). Adjusting for oversampling, we estimated that a combined study sample size of 1054 would provide $90 \%$ power to detect a difference approximating an effect size of 0.2 SD (considered a small effect) on one of the study attitudinal scales (described below) between those with and without a prior depression diagnosis.

\section{Survey Procedures \\ BRFSS Survey}

The BRFSS survey contains 3 components. The core component includes questions asked by all states and asks about current health-related perceptions, conditions and behaviors, and demographic characteristics. The optional modules are sets of questions about specific topics that states elect (as edited and evaluated by the Centers for Disease Control and Prevention) to use in their questionnaires. Questions added by states are developed or acquired by participating states. These questions are not edited or evaluated by Centers for Disease Control and Prevention. A detailed description of the items included in the core component, as well as the optional and state-added items specific to the California version of the BRFSS questionnaire used in 2008, is available elsewhere. ${ }^{37}$ Included in the
California survey was whether or not the respondent reported a history of a depression diagnosis. Other questions germane to this study included age; sex; the highest level of education obtained (categorized in years of schooling completed as $<12,12,13-15,16$, or $>16$ ); household income (categorized in $\$ /$ year as $<20,000,20,000-34,999$, $35,000-49,999,50,000-74,999,75,000-99,999$, or $>100,000$ ); and the availability of health insurance and a usual source of medical care. Interviews were conducted in English or in Spanish, as preferred by the participant. The California BRFSS survey has been administered since 1987 by the Survey Research Group, a section under the California Department of Public Health's Cancer Surveillance and Research Branch.

\section{Follow-Up Survey}

We developed a 20-minute, supplemental, computer-assisted telephone interview designed to assess participants' current depression symptoms (Patient Health Questionnaire [PHQ] 9 ${ }^{38,39}$ ), preferences for future depression treatment, depression illness representation models, perceived depression stigma, beliefs about antidepressant medication, beliefs about counseling, general religious attitudes, and general toughness attitudes. The study protocol was reviewed and approved by the institutional review board at the University of California, Davis. Like the BRFSS survey, this supplemental survey was administered by the Survey Research Group using the same standardized survey procedures. Sampling rates for the follow-up survey were calculated based on the standard definitions of the American Association of Public Opinion Research. ${ }^{40}$ Up to 15 attempts were made to contact each potentially eligible household. Excluding households of unknown eligibility (eg, no answer or no eligibility screening completed), the response rate was 0.49 . The cooperation rate (responding households excluding those in which eligible individuals did not complete the interview or were physically or mentally unable to be interviewed) was 0.61. Given these response rates, 2705 telephone numbers were used to generate the final sample of 1054 completed interviews.

\section{Treatment Preferences in the Follow-Up Survey}

Participants were asked their treatment preference in the event of a future diagnosis of depression. 
Options included (1) taking antidepressant medication daily for at least 6 to 9 months; (2) weekly counseling for at least 2 months; (3) medication and counseling; or (4) wait and see (no treatment). To better represent the modal treatment experience, and in contrast to some other studies, ${ }^{12,13}$ options were constructed so as to include both treatment type and typical duration.

\section{Psychological Measures in the Follow-up Survey}

Psychological measures were multi-item scales. Participants were asked to rate their level of agreement to each item on a 5 -point Likert scale $(1=$ strongly agree, $5=$ strongly disagree) for all the measures except religiosity, which was measured on a 4-point Likert scale. Responses were reversecoded if necessary so that higher scale scores indicated greater levels of the given psychological construct. Two illness representation models were examined: the biomedical and environmental explanatory models. Items for each explanatory model measure were based on the Illness Representation Model and were adapted from previous work. ${ }^{41-43}$ Factor analysis (results not shown) of the Illness Representation Model-based items supported our treatment of the items as 2 distinct constructs, and scales were subsequently produced. The biomedical explanatory model scale included 6 items, and in this sample Cronbach's $\alpha=0.73$. The environmental explanatory model scale included 2 items, and in this sample Cronbach's $\alpha=0.62$. To compare explanatory models with each other, given the differing number of items in each scale, mean scores were used (range, 1-5). For the other psychological measures, scores were summed. The depression stigma scale (3 items; score range, 3-15; Cronbach's $\alpha=0.54$ ) was adapted from Fogel and Ford. ${ }^{44}$ The religiosity scale (4 items; score range, $4-16 ; \alpha=0.87$ ) was adapted from Rohrbaugh and Jessor. ${ }^{45}$ The toughness scale (4 items; score range, $4-20 ; \alpha=0.63)$, which reflects projections of independence, toughness, and denial of needs, was adapted from Fischer et $\mathrm{al}^{46}$ The male-specific wording of the original items was modified to make them gender neutral. Individual items for all scales are provided in Table 1 .

\section{Data Analysis}

All analyses were conducted using Stata (version 11.0; Stata Corp, LP, College Station, TX) and accounted for the complex survey design of both the BRFSS and the subsample of the current survey (which oversampled persons with a depression history) to yield appropriate standard errors and population parameter estimates. Subjects for the current study were sampled from 2 strata: those with and those without a history of depression. California BRFSS weights ${ }^{47}$ were used but were further adjusted for the oversampling of patients with a history of depression. The current analysis was restricted to those persons specifying either Hispanic ethnicity of any race or non-Hispanic ethnicity of white race, reducing the sample size for analysis from 1054 to 978 individuals.

For the purpose of analysis, treatment preferences were dichotomized into options that included antidepressants (taking antidepressants alone or combined with counseling) versus other treatment options (counseling only or wait and see). A series of logistic regression models were constructed to examine this dichotomized preference (dependant variable). To address the first question (treatment preference by ethnicity/interview language), respondents were categorized into non-Hispanic white, English-speaking Hispanic, and Spanish-speaking Hispanic groups (based on interview language). All analyses were adjusted for age, sex, history of depression diagnosis, and depression symptoms (PHQ-9 score). To address the second question (mediation), clusters of putative mediators (independent variables) were separately included in the regression analysis. The clusters were comprised of socioeconomic variables (household income and education); health care access variables (availability of a personal health care practitioner and health insurance, both dichotomized as available or not); and each of the psychological variables (explanatory illness representation model [biomedical and environmental], stigma, toughness, and religiosity). Mediation was assessed by comparing regression coefficients between the models with and without the putative mediation cluster included. Coefficients were compared using the method of Clogg et al, ${ }^{48}$ and were implemented in Stata using the suest program. Confidence intervals around percent mediation effects were derived using Fieller's ${ }^{49}$ method. Finally, all potential mediators were included together to examine possible cumulative effects. 
Biomedical explanatory illness representation model of depression $(\alpha=0.73)$

Environmental explanatory illness representation model of depression $(\alpha=0.62)$

Perceived depression stigma $(\alpha=0.54)$

Religiosity $(\alpha=0.87)$

Toughness $(\alpha=0.63)$
1. Clinical depression is a real medical illness.

2. Chemical imbalances in the brain cause depression.

3. Clinical depression is as serious as other long-lasting medical conditions like diabetes or heart disease.

4. Depression can contribute to physical symptoms like pain or headaches.

5. People with depression should be able to pull themselves out of it without professional help.

6. Most people with depression can fully recover on their own by participating in activities such as exercise, meditation, and socializing with friends and family.

1. Depression is the result of problems in living, such as job stress, money problems, or conflicts with family.

2. Clinical depression is caused by bad experiences in a person's past such as abuse, neglect, or trauma.

1. I would be embarrassed if my friends knew I was getting professional help for an emotional problem.

2. If I had depression, my family would be disappointed with me.

3. I would not want my employer to know I was getting professional help for an emotional problem.

1. How often do you attend religious services? (never, barely, sometimes, often)

2. When you do have problems or difficulties in your work, family or personal life, how often do you seek spiritual comfort? (never, barely, sometimes, often)

3. In general how important are religious or spiritual beliefs in your dayto-day life? (not at all, only somewhat important, very important, extremely important)

4. In general how religious would you say you are? (not at all religious, only somewhat religious, very religious, extremely religious)

1. A person should always try to project an air of confidence even if they really do not feel confident inside.

2. A good motto to live by is, When the going gets tough, the tough get going.

3. When people are feeling a little pain, they should try not to let it show very much.

4. People must stand on their own 2 feet and never depend on other people to help them do things.

The level of agreement with each item was rated on a 5 -point Likert scale $(1=$ strongly agree, $5=$ strongly disagree $)$ for all of the measures except religiosity. Responses were reverse coded if necessary so that higher scale scores indicated greater levels of the given psychological construct.

\section{Results}

\section{Description of the Sample}

The population-weighted characteristics (sociodemographics, clinical and attitudinal characteristics, and health care access) of the Spanish-speaking Hispanic, English-speaking Hispanic, and nonHispanic white respondent subgroups are shown in Table 2. Compared with non-Hispanic white respondents, Hispanic respondents were significantly younger, less likely to be men, less likely to endorse a biomedical explanatory illness representation model, more likely to be religious, more likely to endorse toughness, and have completed fewer years of education. Spanish-speaking Hispanic respon- dents, specifically, were more likely to report higher levels of depressive symptoms on the PHQ-9 and lower household incomes and were less likely to report having a personal health care practitioner or health insurance coverage.

The population-weighted characteristics (sociodemographics, clinical and attitudinal characteristics, and health care access) of all respondents by their preference for depression treatment options are shown in Table 3. Those that preferred treatment options that included antidepressants were significantly less likely to be Spanish-speaking Hispanic respondents and to endorse toughness; they were significantly more likely to be of older age, have 


\begin{tabular}{|c|c|c|c|c|}
\hline \multirow[b]{2}{*}{ Characteristic } & \multicolumn{4}{|c|}{ Ethnicity, Interview Language* } \\
\hline & $\begin{array}{l}\text { Non-Hispanic } \\
\text { White, English }\end{array}$ & $\begin{array}{l}\text { Hispanic, } \\
\text { English }\end{array}$ & $\begin{array}{l}\text { Hispanic, } \\
\text { Spanish }\end{array}$ & $P^{\dagger}$ \\
\hline Totals (n [\%]) & $839(73)$ & $92(15)$ & $47(11)$ & NA \\
\hline Age (years)\$ & $50.9(1)$ & $44.1(2.5)$ & $42(3.5)$ & $<.01$ \\
\hline Male sex $\ddagger$ & $46.5(2.6)$ & $39.9(7.9)$ & $21.5(7.5)$ & .03 \\
\hline History of depression diagnosis $\ddagger$ & $15.4(1.2)$ & $18.4(4.1)$ & $11.5(3.9)$ & .46 \\
\hline PHQ 9 score (range of sums, $0-27) \$$ & $3.3(0.2)$ & $3.4(0.4)$ & $6.7(1)$ & $<.01$ \\
\hline Biomedical explanatory model (range of means, $1-5) \$$ & $4(<0.1)$ & $3.8(<0.1)$ & $3.5(<0.1)$ & $<.01$ \\
\hline Environmental explanatory model (range of means, $1-5) \$$ & $4(<0.1)$ & $4(<0.1)$ & $4.1(0.1)$ & .81 \\
\hline Stigma scale (range of sums, 3-15)§ & $7.6(0.1)$ & $8.1(0.4)$ & $7.9(0.3)$ & .33 \\
\hline Religiosity scale (range of sums, 4-16) $\$$ & $9.4(0.2)$ & $10.9(0.5)$ & $11.5(0.6)$ & $<.01$ \\
\hline Toughness scale (range of sums, 4-20)\$ & $12.3(0.1)$ & $12.7(0.4)$ & $13.9(0.6)$ & .02 \\
\hline \multicolumn{5}{|l|}{ Education (years completed) } \\
\hline$<12 \ddagger$ & $2.3(0.8)$ & $14.2(7.4)$ & $56.9(10.2)$ & $<.01$ \\
\hline $12 \ddagger$ & $14.5(2.1)$ & $26.5(7.7)$ & $12.0(4.8)$ & \\
\hline 13 to $15 \neq$ & $28.5(2.3)$ & $27.5(5.9)$ & $21.4(10.2)$ & \\
\hline $16 \neq$ & $29.8(2.3)$ & $14.0(4.4)$ & $1.5(1.2)$ & \\
\hline$>16 \neq$ & $24.9(2.1)$ & $17.8(5.9)$ & $8.2(5.1)$ & \\
\hline \multicolumn{5}{|l|}{ Income $(\$)$} \\
\hline$<20,000$ ‡ & $8.4(1.2)$ & $9.7(2.9)$ & $50.1(10.2)$ & $<.01$ \\
\hline $20,000-34,999 \ddagger$ & $10.0(1.6)$ & $15.6(4.7)$ & $25.1(7.9)$ & \\
\hline $35,000-49,999 \ddagger$ & $11.4(1.6)$ & $5.6(2.5)$ & $7.9(3.8)$ & \\
\hline $50,000-74,999 \ddagger$ & $18.3(2.1)$ & $28.5(7.8)$ & $16.9(8.4)$ & \\
\hline $75,000-99,999 \ddagger$ & $20.1(2.1)$ & $25.3(8.0)$ & $0(0)$ & \\
\hline$>100,000 \ddagger$ & $31.8(2.5)$ & $15.3(5.1)$ & $0(0)$ & \\
\hline Has personal healthcare practitioner & $85.3(2.1)$ & $86.9(4.1)$ & $41.8(9.6)$ & $<.01$ \\
\hline Has health insurance & $94.2(1.6)$ & $91.4(3.5)$ & $68.4(9.2)$ & $<.01$ \\
\hline
\end{tabular}

*Means/sums and percentages are population weighted.

${ }^{\dagger} P$ values are for $\chi^{2}$ or regression comparisons of all groups to each other.

PHQ, Patient Health Questionnaire.

$\ddagger$ Characteristics using \% (SE).

$\$$ Characteristics using means/sums (SE).

a history of depression diagnosis, endorse a biomedical explanatory illness representation model, and report having a personal health care practitioner or health insurance coverage.

\section{Adjusted Predictors of Preference for Depression Treatment Options That Include Antidepressant Medications}

The adjusted relationships between a preference for treatment options that included antidepressant medications (adjusted odds ratios) and respondent characteristics are shown in Table 4 (models I through III). In the model adjusting only for age, sex, ethnic/interview language groupings, history of depression diagnosis, and current depression symptoms (model I), a preference for treatments that included antidepressants was significantly more likely for older persons and those with a history of depression. Furthermore, addressing the first research question (possible differences between Hispanic respondents), a preference for treatment options that included antidepressants was significantly less likely for Spanish-speaking, but not English-speaking, Hispanic respondents when each were compared with non-Hispanic white respondents.

Addressing the second research question (possible mediation of differences in Hispanic respondents' treatment preferences) when the illness representation models were added (model II), those who endorsed a biomedical explanatory illness representation model were significantly more likely to prefer treatment options that included antidepressants; the effect for Spanish-speaking Hispanic re- 
Table 3. Descriptive Characteristics of the Sample by Depression Treatment Preferences

\begin{tabular}{|c|c|c|c|c|}
\hline \multirow[b]{2}{*}{ Characteristics } & \multicolumn{4}{|c|}{ Treatment Preferences $(\%[\mathrm{SE}])^{*}$} \\
\hline & Medication Only & Medication and Counseling & Counseling Only & Wait and See \\
\hline Total sample $(\mathrm{N}=976)$ & $9.4(1.4)$ & $39.6(2.3)$ & $36.5(2.5)$ & $14.5(2.1)$ \\
\hline \multicolumn{5}{|l|}{ Ethnicity, interview language } \\
\hline Non-Hispanic white $(\mathrm{n}=837)$ & $9.1(1.3)$ & $42.5(2.5)$ & $34.5(2.6)$ & $13.7(1.9)$ \\
\hline Hispanic, English $(\mathrm{n}=92)$ & $11.8(5.5)$ & $39.9(7.5)$ & $31.8(7.8)$ & $16.5(6.5)$ \\
\hline \multirow[t]{3}{*}{ Hispanic, Spanish $(\mathrm{n}=47)$} & $8.2(5.2)$ & $20.9(6.6)$ & $54.5(10.2)$ & $16.4(9.7)$ \\
\hline & & \multicolumn{3}{|c|}{ Dichotomized Treatment Preferences* } \\
\hline & & $\begin{array}{l}\text { Options Including } \\
\text { Medications }^{\dagger}\end{array}$ & $\begin{array}{l}\text { Options Other Than } \\
\text { Medications }^{\ddagger}\end{array}$ & $P^{\S}$ \\
\hline Total sample (N [\%]) & & $588(49.1)$ & $388(50.9)$ & NA \\
\hline \multicolumn{5}{|l|}{ Ethnicity, interview language } \\
\hline Non-Hispanic whiteII & & $77.2(3.1)$ & $69.5(4.2)$ & .05 \\
\hline Hispanic, Englishף & & $15.9(2.8)$ & $14.3(3.2)$ & \\
\hline Hispanic, Spanishף & & $6.9(1.9)$ & $16.2(3.4)$ & \\
\hline Age (years)\| & & $53.2(1.1)$ & $44.6(1.4)$ & $<.01$ \\
\hline Male sex丩 & & $42.0(3.9)$ & $42.4(3.9)$ & .92 \\
\hline History of depression diagnosis $\mathbb{I}$ & & $23.0(1.6)$ & $8.6(1.2)$ & $<.01$ \\
\hline $\begin{array}{l}\text { Patient Health Questionnaire-9 Sc } \\
\quad 0-27) \|\end{array}$ & (range of sums, & $4.1(0.3)$ & $3.4(0.4)$ & .14 \\
\hline Biomedical Explanatory Model (ra & of means, $1-5) \|$ & $4.1(<0.1)$ & $3.7(<0.1)$ & $<.01$ \\
\hline Environmental explanatory model & nge of means, 1-5)\| & $2.0(<0.1)$ & $2.0(<0.1)$ & .92 \\
\hline Stigma scale (range of sums, 3-15) & & $7.6(0.2)$ & $7.8(0.2)$ & .23 \\
\hline Religiosity scale (range of sums, 4 & & $9.8(0.2)$ & $9.9(0.3)$ & .83 \\
\hline Toughness scale (range of sums, 4 & & $12.2(0.2)$ & $12.8(0.2)$ & .03 \\
\hline \multicolumn{5}{|l|}{ Education (years completed) } \\
\hline$<12 \mathbb{1}$ & & $7.4(1.9)$ & $13.1(3.4)$ & .20 \\
\hline $12 \mathbb{1}$ & & $14.9(2.5)$ & $17.0(3.3)$ & \\
\hline $13-15 \mathbb{I}$ & & $25.9(2.6)$ & $29.1(3.4)$ & \\
\hline $16 \mathbb{1}$ & & $26.5(2.6)$ & $21.8(2.9)$ & \\
\hline$>16 \mathbb{I}$ & & $25.2(2.7)$ & $18.9(2.6)$ & \\
\hline \multicolumn{5}{|l|}{ Income $(\$)$} \\
\hline$<20,0000 \mathbb{I}$ & & $10.7(1.6)$ & $16.2(3.4)$ & .08 \\
\hline 20,000-34,999व & & $14.8(2.4)$ & $10.6(2.2)$ & \\
\hline $35,000-49,999$ II & & $10.1(1.8)$ & $10.0(2.0)$ & \\
\hline $50,000-74,999 \mathbb{I}$ & & $18.0(2.6)$ & $21.3(3.6)$ & \\
\hline $75,000-99,999 \mathbb{1}$ & & $15.8(2.2)$ & $21.1(3.4)$ & \\
\hline$>100,000 \mathbb{I}$ & & $30.5(2.9)$ & $20.7(2.9)$ & \\
\hline Has personal healthcare practition & & $84.8(2.6)$ & $76.3(3.8)$ & .05 \\
\hline Has any health insuranceII & & $94.1(1.7)$ & $87.6(2.9)$ & .04 \\
\hline
\end{tabular}

Notes: *Means/sums and percentages are population-weighted

${ }^{\dagger}$ Medication only taken for at least 6 to 9 months + medication with counseling.

${ }^{\ddagger}$ Counseling only weekly for at least 2 months + wait and see.

${ }^{\$} P$ values are for $\chi^{2}$ or regression comparisons of all groups to each other.

ФCharacteristics using \% (SE).

\|Characteristics using means/sums (SE).

spondents was attenuated (became nonsignificant). The attenuation of the effect for Spanish-speaking Hispanic respondents was significant; that is, addition of the biomedical explanatory illness represen- tation model explained $73 \%$ (95\% CI, 39-100) of the effect for Spanish-speaking Hispanic respondents. Of the remaining variables in model II, sex, level of current depression symptoms, and the environmental 


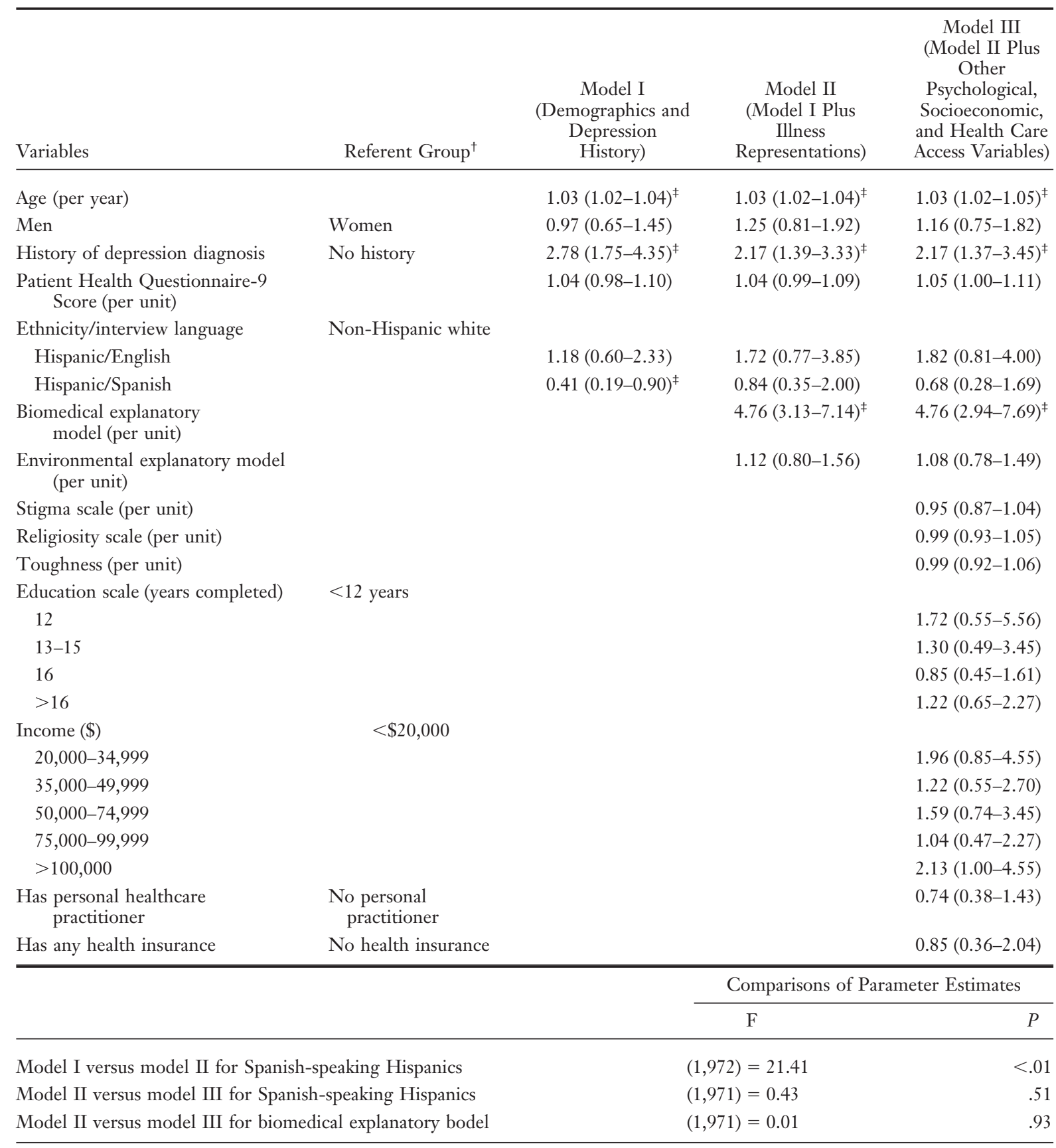

Values provided as adjusted odds ratio (AOR) (95\% CI). For all comparisons of continuous variables, AORs are per unit (year, mean, or sum).

*Includes responses for the whole sample $(\mathrm{N}=978)$.

${ }^{\dagger}$ For all comparisons of categorical variables, the "referent groups" as specified in the table have an AOR = 1, to which other categories for that variable are compared. For simplicity, these referent groups' AORs are not shown.

${ }^{\ddagger}$ Significant AOR (95\% CI does not include 1).

explanatory illness representation model exhibited no significant effect on preferences for treatment options that included antidepressants, whereas older age and a history of depression diagnosis remained significant.
Furthermore, none of the other putative mediators that were separately included in the analysis (income, education, stigma, religiosity, toughness, having a personal health care practitioner, and having health 
insurance) exhibited any significant mediation of the relationships between Spanish-language interview, older age, history of depression diagnosis, and preference for treatment options that included antidepressants (data not shown).

When the remaining variables (income, education, stigma, religiosity, toughness, having a personal health care practitioner, and having health insurance) were collectively added to the model (model III) to examine for possible cumulative effects, the relationships between the variables already in the model (model II) were not significantly altered. None of the variables (putative mediators) added in model III from model II made a statistically significant contribution.

Taken together, models I through III in Table 4 show that for all respondents only older age, a history of depression diagnosis, and endorsing a biomedical explanatory illness representation model were associated with higher odds of preferring treatment options that included antidepressants. Spanish-language interview was also associated with significantly lower odds of preferring treatment options that included antidepressants, an effect observed only when the biomedical explanatory illness representation model was not included in the analytic model.

\section{Discussion}

Using data from a statewide population-based survey, we found significant heterogeneity within the Hispanic population in preferences for the most commonly offered depression treatment options in primary care. ${ }^{18}$ Spanish-speaking Hispanic respondents were less likely to indicate preferences for options that included antidepressants than were English-speaking Hispanic and non-Hispanic white respondents. In addition, a biomedical explanatory illness representation model of depression was a powerful predictor of preference for treatment options that included antidepressants in all interview language/ethnicity groups (along with age and a history of depression diagnosis), and it mediated the effect of interview language on treatment preference among Spanish-speaking Hispanic respondents.

Language preference (Spanish vs English) is a subgroup-defining characteristic commonly used by researchers examining heterogeneity in and clinicians delivering care to the Hispanic population. Similarly, the focus of our study was not to inves- tigate how language itself influences preferences for treatment options that include antidepressants. Rather, language preference may be viewed as a readily assessed marker for more complex, less easily defined and measured social characteristics that predict behavior. ${ }^{26}$ For example, some have argued that language preference is essentially a marker for access to health $\operatorname{care}^{25}$; yet others have shown that differences in antidepressant use persist for Spanish-speaking Hispanic persons despite controlling for access. ${ }^{50}$ Preferred language is more often viewed as a proxy for acculturation that subsumes other equally important Hispanic population characteristics such as race, socioeconomic status, nativity, and generation, rather than as a marker for health care access. ${ }^{14,22-24}$

To investigate these complex relationships, we examined possible mediators of attitudes toward antidepressant medication preference, adjusting for characteristics other than language/ethnicity associated with treatment preferences (history of depression diagnosis, current depression symptoms, age, and sex). Though a history of depression diagnosis (possibly because of treatment experience) and older age (possibly because of a higher likelihood of depression diagnosis with increasing age) were associated with a preference for treatment options containing antidepressants for all respondents, only a biomedical explanatory illness representation model of depression was found to mediate the effect of Spanish-language interview on the lower preference for pharmacologic treatment options among Spanish-speaking Hispanic respondents. Furthermore, this illness representation model itself was found to be an important predictor of these preferences among all groups when accounting for other factors. Variations in depression illness representations between ethnic groups ${ }^{51}$ and within the Hispanic population ${ }^{52}$ have been previously demonstrated. Illness representations have been identified as important predictors of treatment for other medical conditions ${ }^{28,29}$ and, more specifically, have been postulated as an important mediator of depression treatment among Hispanics. ${ }^{53,54}$ Our study adds to the limited existing evidence for this connection between illness representation models and depression treatment preference. . $^{15,30,55}$

Antidepressants are the most commonly available depression treatment in primary care, ${ }^{7}$ in part because of provider attitudes ${ }^{56}$ and barriers limiting access to counseling services. ${ }^{8}$ Furthermore, the 
addition of antidepressants to counseling may be more effective in treating depression than counseling alone among selected patients. ${ }^{17}$ Therefore, among Spanish-speaking Hispanic patients who are presented with treatment plans including antidepressants, resistance to such plans created by a lower preference for antidepressants may represent one important barrier to initiating or adhering to effective depression care in the primary care setting. Though our findings may apply at the population level, the clinical implications should be assessed cautiously.

Stereotyping Spanish-speaking Hispanic patients as "reluctant" to consider antidepressants without addressing individual depression explanatory models (as our mediation findings highlight) or treatment preferences could worsen disparities in depression care by denying antidepressant treatments to individuals for whom it might be both welcome and effective. Clinicians should avoid making assumptions based on population-level data and consider age, history of depression treatment, and each individual patient's depression explanatory model (significant predictors in this analysis) along with culturally based treatment beliefs as part of developing a therapeutic plan. Similarly, those involved in clinical resource planning should consider these factors along with population characteristics such as ethnicity when allocating treatment resources. Ameliorating reluctance to use antidepressant medication may be achieved through health education and provider communication interventions implemented in primary care offices. ${ }^{9,10}$ The role of cross-cultural education for both primary care practitioners $^{57,58}$ and designers of mental health care delivery systems may be essential to such targeted efforts.

Our study has some limitations. Data were drawn from a cross-sectional survey, so causal pathways cannot be established. Although results were weighted for nonresponse and telephone availability, the findings may be biased by telephone access, self-selection of call-back participation, recall bias, and the low response rate of the BRFSS. Despite being a population-based study, there were also only small numbers of respondents in each of the analytic subgroups of Hispanic respondents, which could have led to false-negative results. Furthermore, as discussed, dimensions of cultural identity other than language among Hispanic persons that might influence treatment attitudes, such as length of residence in the United States, nativity, and race, were either unavailable or were insufficiently measured because of small sample size for inclusion in our analyses. These two interrelated limitations to the generalizability of the findings may be especially relevant to our results for depression stigma, which has been shown in previous studies of Hispanic individuals to have a robust association with depression treatment preferences. ${ }^{59,60}$ Additionally, our attitudinal measures were adaptations of previously developed scales. Finally, given the format of our depression treatment choices, options such as spirituality-based interventions, which may be important in some populations, ${ }^{61}$ could not be fully explored.

\section{Conclusion}

We found that Spanish-speaking Hispanic respondents participating in the California BRFSS were less likely to endorse treatment with antidepressants than were English-speaking Hispanic and non-Hispanic white respondents, and that this difference may be because of differences in underlying depression explanatory illness representation models. Greater understanding of factors leading to barriers to depression treatment in the settings where that treatment most frequently occurs can help direct targeted interventions to overcome these barriers effectively. Such coordinated steps may lead to improvement of depression outcomes. Our study suggests that understanding the mechanisms of depression treatment barriers to improve depression care for the Hispanic patients would benefit from further, larger studies among this heterogeneous population.

\section{References}

1. Lagomasino IT, Dwight-Johnson M, Miranda J, et al. Disparities in depression treatment for Latinos and site of care. Psychiatr Serv 2005;56:1517-23.

2. Institute of Medicine. Unequal treatment: confronting racial and ethnic disparities inh. Washington, DC: National Academies Press; 2003.

3. Young AS, Klap R, Sherbourne CD, Wells KB. The quality of care for depressive and anxiety disorders in the United States. Arch Gen Psychiatry 2001;58: 55-61.

4. US Census Bureau. Facts for features CBO7-FF14. Hispanic Heritage Month 2007: Sept 15-Oct 15. Available at http://www.census.gov/newsroom/releases/ archives/facts_for_features_special_editions/cb07-ff14.html. Accessed August 25, 2010. 
5. Vega WA, Kolody B, Aguilar-Gaxiola S. Help seeking for mental health problems among Mexican Americans. J Immigr Health 2001;3:133-40.

6. Olfson M, Shea S, Feder A, et al. Prevalence of anxiety, depression and substance abuse disorders in an urban general medicine practice. Arch Fam Med 2000;9:876-83.

7. Robinson WD, Geske JA, Prest LA, Barnacle R. Depression treatment in primary care. J Am Board Fam Pract 2005;18:79-86.

8. Substance Abuse and Mental Health Services Administration. Reimbursement of mental health services in primary care settings. Rockville, MD: U.S. Department of Health and Human Services; 2008.

9. Lin P, Campbell DG, Chaney EF, et al. The influence of patient preference on depression treatment in primary care. Ann of Behav Med 2005;30:164-73.

10. Cooper LA, Brown C, Vu HT, et al. Primary care patients' opinions regarding the importance of various aspects of care for depression. Gen Hosp Psychiatry 2000;22:163-73.

11. Karasz A, Watkins L. Conceptual models of treatment in depressed Hispanic patients. Ann of Fam Med 2006;4:527-33.

12. Cooper LA, Gonzales JJ, Gallo JJ, et al. The acceptability of treatment for depression among AfricanAmerican. Hispanic, and White primary care patients. Med Care 2003;41:479-89.

13. Dwight-Johnson M, Lagomasino IT, Aisenberg E, Hay J. Using conjoint analysis to assess depression treatment preferences among low-income Latinos. Psychiatr Serv 2004;55:934-6.

14. Cabassa LJ, Lester R, Zayas LH. "It's like a labyrinth": Hispanic immigrants' perceptions of depression and attitudes toward treatments. J Immigr Health 2007;9:1-16.

15. Givens JL, Houston TK, Van Voorhees BW, Ford DE, Cooper LA. Ethnicity and preferences for depression treatment. Gen Hosp Psychiatry 2007;29: 182-91.

16. Dwight-Johnson M, Sherbourne CD, Liao D, Wells KB. Treatment preferences among depressed primary care patients. J Gen Intern Med 2000;15:527-34.

17. Hollon SD, Jarrett RB, Nierenberg AA, Thase ME, Trivedi M, Rush AJ. Psychotherapy and medication in the treatment of adult and geriatric depression: which monotherapy or combined treatment? J Clin Psychiatry 2005;66:455-68.

18. Rust G, Daniels E, Bacon J, Satcher D, Strothers H, Bornemann T. Ability of community health centers to obtain mental health services for uninsured patients. JAMA 2005;293:554-6.

19. Lara M, Gamboa C, Kahramanian MI, Morales LS, Bautista DE. Acculturation and Latino health in the United States: a review of the literature and its sociopolitical context. Annu Rev Public Health 2005; 26:367-97.

20. Vega WA, Kolody B, Aguilar-Gaxiola S, Catalano R.
Gaps in service utilization by Mexican Americans with mental health problems. Am J Psychiatry 1999; 156:928-34.

21. Guarnaccia PJ, Pincay IM, Alegria M, Shrout P, Lewis-Fernandez R, Canino G. Assessing diversity among Latinos: results from the NLAAS. Hisp J Behav Sci 2007;29:510-34.

22. Ruiz P. Spanish, English, and mental health services. Am J Psychiatry 2007;164:1133-5.

23. Folsom DP, Gilmer T, Concepcion B. A longitudinal study of the use of mental health services by persons with serious mental illness: Do Spanish-speaking Latinos differ from English-speaking Latinos and Caucasians? Am J Psychiatry 2007;164:1173-80.

24. Hunt LM, Schneider S, Comer B. Should "acculturation" be a variable in health research? A critical review of research on U.S. Hispanics. Soc Sci Med 2004;59:973-86.

25. Thomson MD, Hoffman-Goetz L. Defining and measuring acculturation: a systematic review of public health studies with Hispanic populations in the United States. Soc Sci Med 2009;69:983-91.

26. Perez-Stable EJ. Language access and Latino health care disparities. Med Care 2007;45:1009-11.

27. van Schaik DJ, Klijn AF, van Hout HP, et al. Patients' preferences in the treatment of depressive disorder in primary care. Gen Hosp Psychiatry 2004; 26:184-9.

28. Haggar MS, Orbell S. A meta-analytic review of the common-sense model of illness representation. Psychology \& Health 2003;18:141-84.

29. Petrie KJ, Jago LA, Devich DA. The role of illness perceptions in patients with medical illness. Curr Opin Psychiatry 2007;20:163-7.

30. Brown C, Battista DR, Sereika SM, Bruehlman RD, Dunbar-Jacob J, Thase ME. Primary care patients' personal illness models for depression: relationship to coping behavior and functional disability. Gen Hosp Psychiatry 2007;29:492-500.

31. Sirey JA, Bruce ML, Alexopoulos GS, et al. Perceived stigma as a predictor of treatment discontinuation in young and older outpatients with depression. Am J Psychiatry 2001;158:479-81.

32. Cooper-Patrick L, Powe NR, Jenckes MW, Gonzales JJ, Levine DM, Ford DE. Identification of patient attitudes and preferences regarding treatment of depression. J Gen Intern Med 1997;12:431-8.

33. Cochran SV, Rabinowitz FE. Gender-sensitive recommendations for assessment and treatment of depression in men. Professional Psychology: Research and Practice 2003;34:132-40.

34. Addis ME. Gender and depression in men. Clinical Psychology: Science and Practice 2008;15(3):153-68.

35. Mahalik JR, Locke BD, Ludlow LH, et al. Development of the Conformity to Masculine Norms Inventory. Psychol Men Masc 2003;34:132-40.

36. Ayalon L, Young MA. Racial group differences in 
help-seeking behaviors. J Soc Psychol 2005;145:391403.

37. Centers for Disease Control and Prevention. Behavioral Risk Factor Surveillance System Survey Questionnaire. Atlanta, GA: U.S. Department of Health and Human Services, Centers for Disease Control and Prevention; 2008.

38. Kroenke K, Spitzer RL, Williams JBW. The PHQ-9: validity of a brief depression severity measure. J Gen Intern Med 2001;16:606-13.

39. Lowe B, Kroenke K, Herzog W. Measuring depression outcome with a brief self-report instrument: sensitivity to change of the Patient Health Questionnaire (PHQ-9). J Affect Disord 2004;81:61-6.

40. The American Association for Public Opinion Research. Standard Definitions: Final Dispositions of Case Codes and Outcome Rates for Surveys. Revised 2009. Available at: http://www.aapor.org/AM/Template. $\mathrm{cfm}$ ?Section $=$ Standard_Definitions\&Template $=/ \mathrm{CM} /$ ContentDisplay.cfm\&ContentID $=1819$. Accessed August 25, 2010.

41. Moss-Morris R, Weinman J, Petrie KJ, Horne R, Cameron LD, Buick D. The Revised Illness Perception Questionnaire (IPQ-R). Psychology \& Health 2002;17:1-16.

42. Brown C, Dunbar-Jacob J, Palenchar DR, et al. Primary care patients' personal illness models for depression: a preliminary study. Fam Pract 2001;18: 314-20.

43. Weinman J, Petrie KJ, Moss-Morris-R, Horne R. The Illness Perception Questionnaire: a new method for assessing the cognitive representation of illness. Psychology \& Health 1996;11:431-45.

44. Fogel J, Ford DE. Stigma beliefs of Asian Americans with depression in an internet sample. Can J Psychiatry 2005;50:470-8.

45. Rohrbaugh J, Jessor R. Religiosity in youth: a personal control against deviant behavior. J Pers 1975; 43:136-55.

46. Fischer AR, Tokar DM, Good GE, Snell AF. More on the structure of male role norms. Exploratory and multiple sample confirmatory analyses. Psychol Women Q 1998;22:135-55.

47. Centers for Disease Control and Prevention. BRFSS Annual Survey data. Survey data and documentation. BRFSS weighting formula. Available at: $b t t p: / /$ wwww.cdc.gov/BRfss/technical_infodata/weighting.htm. Accessed May 14, 2010.

48. Clogg CC, Petkova E, Haritou A. Statistical methods for comparing regression coefficients between models. AJS 1995;100:1261-93.
49. Fieller EC. Some problems in interval estimation. J R Stat Soc Ser B Stat Methodol 1954;16:175-83.

50. Gonzalez HM, Tarraf W, West BT, et al. Antidepressant use in a nationally representative sample of community-dwelling U.S. Latinos with and without depressive and anxiety disorders. Depress Anxiety 2009;26:674-81.

51. Karasz A. Cultural differences in conceptual models of depression. Soc Sci Med 2005;60:1625-35.

52. Karasz A, Sacajiu G, Garcia N. Conceptual models of psychological distress among low-income patients in an inner-city primary care clinic. J Gen Intern Med 2003;18:475-7.

53. Cabassa LJ, Lagomasino IT, Dwight-Johnson M, Hansen MC, Xie B. Measuring Latinos' perceptions of depression: a confirmatory factor analysis of the Illness Perception Questionnaire. Cultur Divers Ethnic Minor Psychol 2008;14:377-84.

54. Cabassa LJ, Hansen MC, Palinkas LA, Ell K. Azúcar y nervios: explanatory models and treatment experiences of Hispanics with diabetes and depression. Soc Sci Med 2008;66:2413-24.

55. Karasz A. The development of valid subtypes for depression in primary care settings: a preliminary study using an explanatory model approach. J Nerv Ment Dis 2008;196:289-96.

56. Daniels ML, Linn LS, Ward N, Leake B. A study of physician preferences in the management of depression in the general medical setting. Gen Hosp Psychiatry 1986;8:229-35.

57. Tervalon M, Murray-Garcia J. Cultural Humility versus cultural competence: a critical distinction in defining physician training outcomes in multicultural education. J Health Care Poor Underserved 1998;9:117-25.

58. Smith WR, Betancourt JR, Wynia MK, et al. Recommendations for teaching about racial and ethnic disparities in health and health care. Ann Intern Med 2007;147:654-65.

59. Interian A, Ang A, Gara MA, Link BG, Rodriguez MA, Vega MA. Stigma and depression treatment utilization among Latinos: utility of four stigma measures. Psychiatr Serv 2010;61:373-9.

60. Nadeem E, Lange JM, Edge D, Fongwa M, Belin T, Miranda J. Does stigma keep poor young immigrant and U.S.-born Black and Latina women from seeking mental health care? Psychiatr Serv 2007;58:1547-54.

61. Nadeem E, Lange JM, Miranda J. Mental health care preferences among low-income and minority women. Arch Womens Ment Health 2008;11:93-102. 